\title{
Predictors of relapse to significant alcohol drinking after liver transplantation
}

\author{
Zamil Karim MD ${ }^{1}$, Pongphob Intaraprasong MD FRCPC ${ }^{1}$, Charles H Scudamore MD FRCSC ${ }^{2}$, \\ Siegfried R Erb MD FRCPC ${ }^{1}$, John G Soos PhD ${ }^{3}$, Elsie Cheung PhD³ , Polly Cooper MSW ${ }^{4}$, \\ Andrzej K Buzckowski MD FRCSC2 , Stephen W Chung MD PhD FRCSC², \\ Urs P Steinbrecher MD FRCPC ${ }^{1}$, Eric M Yoshida MD MHSC FRCPC ${ }^{1}$
}

\begin{abstract}
Z Karim, P Intaraprasong, CH Scudamore, et al. Predictors of relapse to significant alcohol drinking after liver transplantation. Can J Gastroenterol 2010;24(4):245-250.
\end{abstract}

BACKGROUND: End-stage alcoholic liver disease is common, with many of these patients referred for liver transplantation (LT). Alcohol relapse after LT can have detrimental outcomes such as graft loss and can contribute to a negative public perception of LT.

OBJECTIVE: To identify factors that predict the recurrence of harmful alcohol consumption after LT.

METHODS: A total of 80 patients who underwent LT for alcoholic cirrhosis or had significant alcohol consumption in association with another primary liver disease, from July 1992 to June 2006 in British Columbia, were retrospectively evaluated by chart review. Several demographic-, psychosocial- and addiction-related variables were studied. Univariate and multivariate logistic regression analyses were used to test possible associations among the variables studied and a return to harmful drinking after LT.

RESULTS: The relapse rate of harmful alcohol consumption post-liver transplant was $10 \%$, with two patient deaths occurring directly as a result of alcohol relapse. Univariate analysis revealed relapse was significantly associated with pretransplant abstinence of less than six months $(\mathrm{P}=0.003)$, presence of psychiatric comorbidities $(\mathrm{P}=0.016)$, female sex $(\mathrm{P}=0.019)$ and increased personal stressors $(\mathrm{P}=0.044)$, while age at transplant of younger than 50 years approached significance $(\mathrm{P}=0.054)$. Multivariate logistic regression analysis revealed the following independent factors for relapse: pretransplant abstinence of less than six months (OR 77.07; standard error 1.743; $\mathrm{P}=0.013$ ) and female sex (OR 18.80; standard error $1.451 ; \mathrm{P}=0.043$ )

CONCLUSION: The findings of the present study strongly support a required minimum of six months of abstinence before LT because duration of abstinence was found to be the strongest predictor of recidivism. Female sex, younger age at transplant and psychiatric comorbidities were also associated with relapse to harmful drinking.

\section{Les prédicteurs de reprise d'une importante consommation d'alcool après une greffe du rein}

\begin{abstract}
HISTORIQUE : La stéatose hépatique alcoolique terminale est courante et bon nombre des patients sont aiguillés vers une greffe du foie (GF). Une reprise de la consommation d'alcool après une GF peut avoir des résultats néfastes, tels qu'une perte de la greffe, et peut contribuer à une perception publique négative de la GF.
\end{abstract}

OBJECTIF : Repérer les facteurs qui prédisent la reprise d'une consommation néfaste d'alcool après une GF.

MÉTHODOLOGIE : Au total, 80 patients qui avaient subi une GF en raison d'une cirrhose alcoolique ou qui consommaient beaucoup d'alcool en association à une maladie hépatique, opérés entre juillet 1992 et juin 2006 en Colombie-Britannique, ont subi une évaluation rétrospective de leur dossier. Les chercheurs ont étudié plusieurs variables démographiques, psychosociales et liées à la dépendance. Ils ont utilisé les analyses de régression univariée et multivariée pour vérifier des associations possibles entre les variables à l'étude et une reprise de la consommation néfaste d'alcool après une GF.

RÉSULTATS : Le taux de reprise de consommation néfaste d'alcool après une GF s'élevait à $10 \%$, deux décès y étant directement reliés. L'analyse univariée a révélé que cette reprise s'associait de manière significative à une abstinence de moins de six mois avant la greffe $(\mathrm{P}=0,003)$, à la présence de comorbidités psychiatriques $(\mathrm{P}=0,016)$, au sexe féminin $(\mathrm{P}=0,019)$ et à une augmentation des facteurs de stress personnel $(\mathrm{P}=0,044)$, tandis que le fait d'avoir moins de 50 ans avant la greffe était presque significatif $(P=0,054)$. L'analyse de régression logistique multivariée a révélé les facteurs indépendants de rechute suivants : abstinence de moins de six mois avant la greffe (RRR 77,07; erreur standard 1,743; $\mathrm{P}=0,013$ ) et sexe féminin ( $R R R$ 18,80; erreur standard 1,451; $\mathrm{P}=0,043$ ).

CONCLUSION : Les observations tirées de la présente étude étayent solidement une période minimale de six mois d'abstinence avant la GF puisque la durée de l'abstinence est le principal prédicteur de récidive. Le sexe féminin, un jeune âge au moment de la greffe et des comorbidités psychiatriques s'associaient également à une reprise de la consommation néfaste d'alcool.

Key Words: Abstinence; Alcohol; Liver; Recidivism; Relapse; Transplantation

A lcoholic liver disease (ALD) is the most common cause of cirrhosis in Western countries and is second only to viral hepatitis as an indication for orthotopic liver transplantation (LT) in the United States (1). In British Columbia, pure alcoholic cirrhosis accounts for approximately $10 \%$ of all LTs and referrals (unpublished data); however, alcohol consumption is considered to be a significant clinical covariable in many individuals with other primary liver diseases (eg, hepatitis C). As

LT improves in both efficacy and outcome, the demand for liver grafts continues to exceed demand by a growing margin. In the present era of organ donation shortages, LT in patients with a history of alcoholic dependency remains a controversial issue (2). Many believe that alcoholic liver disease is selfinflicted and a result of behavioural choices and, therefore, these individuals should be given lower priority for organ allocation. In fact, Neuberger et al (3) found that nontransplant

${ }^{1}$ Department of Medicine; ${ }^{2}$ Department of Surgery, University of British Columbia; ${ }^{3}$ Department of Psychology; ${ }^{4}$ Department of Social Work,

Vancouver General Hospital and the BC Transplant Society, Vancouver, British Columbia

Correspondence: Dr Eric M Yoshida, Division of Gastroenterology, Vancouver General Hospital, Diamond Health Care Centre, 5153-2775

Laurel Street, Vancouver, British Columbia V5Z 1M9. Telephone 604-875-5371, fax 604-875-5447, e-mail eric.yoshida@vch.ca

Received for publication May 22, 2009. Accepted August 5, 2009 
physicians were twice as likely as the general public to consider a patient with a history of alcohol abuse to be unsuitable for transplant. However, alcoholism has long been classified as a distinct mental disorder by addiction specialists and psychiatrists according to the Diagnostic and Statistical Manual of Mental Disorders IV criteria (4). Thus, it is argued that patients with ALD, as the result of their alcohol dependency, deserve equal consideration for transplantation as those with liver disease from other causes.

Multiple studies (5-10) have found that ALD patients selected for LT have similar, if not better, overall survival compared with their nonalcoholic counterparts. Commentary from the United States (11) suggested that LT may be an underused option for individuals with ALD. The main concern is the risk for recidivism. The reported rates of alcohol relapse post-transplant range from $12.1 \%$ to $45.6 \%(12,13)$. In these patients, it has been found that overall survival is significantly reduced because they are more likely to damage their graft from either direct alcohol toxicity or, more commonly, from medical noncompliance with the immunosuppressive regimen and follow-up appointments (10). Recidivists have also been found to be at increased risk of death from cardiovascular events and malignancies (6). Therefore, it is imperative to identify risk factors that reliably predict recidivism to select patients who will benefit the most from their transplant, and to enable targeted counselling and follow-up to prevent a return to the damaging pattern of alcohol consumption in those transplanted. Despite several studies in the field, no reliable risk factors have been identified that consistently predict post-transplant recidivism, especially in the minority who return to heavy drinking $(7,14,15)$. This includes having less than six months of pretransplant abstinence that is required by most transplant centres. This requirement, however, has been recently challenged (12), with the suggestion that three months of abstinence may be more appropriate, as well as any consistent psychosocial or demographic factors $(14,16)$.

Between July 1992 and June 2006, 80 patients in British Columbia underwent LT either for alcoholic cirrhosis or had a history of excessive and habitual alcohol consumption with another primary liver disease (eg, hepatitis $\mathrm{C}$ ). We conducted a retrospective analysis of these 80 patients with the following aims: to identify risk factors for recurrent alcohol consumption after orthotopic LT, to analyze the long-term outcomes of transplant recipients with alcohol dependency and to evaluate the screening process implemented at our centre (Department of Medicine, University of British Columbia [Vancouver, British Columbia]).

\section{METHODS}

Patients with a history of alcohol abuse who underwent LT at the Vancouver General Hospital (Vancouver, British Columbia) between July 1992 and June 2006, were identified by a retrospective review of medical records. Records were obtained from the Vancouver and Fraser Valley offices of the BC Transplant Society, as well as the Solid Organ Transplant Clinic at the Vancouver General Hospital. All patients were determined to have either a primary diagnosis of ALD or a history of alcohol abuse, with another primary cause of cirrhosis, by the transplant hepatologists/transplant surgeon based on history, laboratory and/or pathological evaluation, and after interview by experienced transplant psychologists and a transplant social worker. All patients were evaluated by the BC Transplant Society and the majority underwent transplantion at the Vancouver General Hospital. Transplant candidates were evaluated by a transplant team, consisting of a physician, transplant psychologists or psychiatrist, and a social worker, and were selected for orthotopic LT if deemed to be at low risk for relapse post-transplant. All patients were also assessed and cleared by a community alcohol and addictions counsellor who was independent of the transplant program. In general, patients were required to be abstinent for at least a six-month period, to not actively use illicit drugs and to enrol in an alcohol rehabilitation program if deemed necessary by the transplant team. All patients referred for liver transplantation, however, were assessed on a case-by-case basis. If a patient with significant hepatic decompensation could not survive to achieve six months of abstinence and the referring physicians believed strongly that the likelihood of post-transplant recidivism was low, and if the evaluation from the transplant psychologists and social worker was reasonable, then the patient could still be listed for transplantation. After LT, recipients underwent biweekly laboratory tests, including liver enzymes, for the first two months and monthly follow-up visits thereafter.

From a review of the literature and using the available data, a list of demographic-, psychosocial- and addiction-related variables were selected a priori and examined (Table 1). Harmful drinking was defined as that associated with medical or social harm, or a return to daily consumption of alcohol. The number of grams of alcohol consumed daily was calculated based on the following assumptions: one beer was equivalent to $355 \mathrm{~mL}$ of $4 \%$ alcohol, one glass of wine as $150 \mathrm{~mL}$ of $11.4 \%$ alcohol, one mixed drink/shot as $37 \mathrm{~mL}$ of $40 \%$ alcohol, one 'mickey' as $375 \mathrm{~mL}$ of $40 \%$ alcohol and one bottle of scotch whiskey as $750 \mathrm{~mL}$ of $40 \%$ alcohol with $0.789 \mathrm{~g} / \mathrm{mL}$. Binge drinking was defined as five or more drinks for men, and four drinks for women in a $2 \mathrm{~h}$ period, and 'frequent' drinking assumed to be three times per week according to the National Institute of Alcohol Abuse and Alcoholism (Maryland, USA) (17). Poor socioeconomic status was defined as a predicted household income of less than $\$ 25,000$ per year or being on disability, income assistance or unemployment. Increased personal stressors were defined as a longstanding source of increased anxiety and psychological tension causing impairment to an individual's daily life. This included domestic abuse, marital break-up, traumatic life event with post-traumatic stress disorder and mental illness that was not well controlled. Psychiatric conditions were those diagnosed by a psychiatrist, which included major depressive disorder, anxiety disorder, schizophrenia and severe personality disorders causing impaired daily functioning.

Statistical significance was evaluated at the conventional alpha $=0.05$ level. Continuous variables were expressed as mean \pm SD (also median and range), and categorical variables as counts (percentages). Comparative $\mathrm{P}$ values of the parametric tests were reported throughout. Independent sample $t$ tests were used to compare the differences between mean values. Nonparametric Mann-Whitney tests were also applied. Categorical variables were evaluated by tests of independence, Fisher's exact or Yates corrected $\chi^{2}$ tests as applicable to $2 \times 2$ contingency tables. Univariate and multivariate Cox logistic regressions were applied to 
identify significant predictors for recidivism. Univariate Cox logistic regressions were applied to each of the independent variables (ie, potential risk factors) of clinical interest. Several stepwise logistic multivariate regression analyses (eg, forward likelihood ratio method) were also tried to identify significant predictors for recidivism. All analyses were performed using SPSS version 15.0 (SPSS Inc, USA) for Windows (Microsoft Corporation, USA).

\section{RESULTS}

Between July 1992 and June 2006, 504 patients underwent LT for end-stage ALD in the province of British Columbia. Of these, 80 patients had either a primary diagnosis of ALD or had a history of alcohol abuse with another primary cause of cirrhosis, representing $16 \%$ of the total. Eight (10\%) of these patients relapsed to harmful drinking. Of the 80 patients, 35 patients had hepatitis $\mathrm{C}$ infection, two patients had alpha- 1 antitrypsin deficiency, one had hemochromatosis and one had primary biliary cirrhosis. Three patients had a diagnosis of hepatocellular carcinoma in their explanted livers. Additional patient characteristics were grouped into alcohol nonrelapsers and relapsers and summarized in Table 1.

A comparison of the two groups (ie, post-transplant relapse versus abstinence [Table 1]) revealed that those who relapsed to alcohol post-transplant were more likely to be women $(\mathrm{P}=0.021)$ and have a younger median age at time of transplant (43.9 years versus 51.2 years; $\mathrm{P}=0.004)$. Univariate analysis further revealed that the relapse group had a much shorter period of stated abstinence before transplant (median nine months versus 26 months in the nonrelapse group; $\mathrm{P}<0.001$ ), and be more likely to have been abstinent from alcohol for less than one year pretransplant ( $57 \%$ versus $14 \%$ in the nonrelapse group; $\mathrm{P}=0.019)$. Documented psychiatric conditions pretransplant $(\mathrm{P}=0.018)$ and increased personal stressors $(\mathrm{P}=0.050)$ were also associated with harmful recidivism. The other factors measured did not achieve statistical significance (all $\mathrm{P}>0.05$ ).

A stepwise, multivariate logistic regression analysis based on the four independent predictor variables (abstinence for less than six months, pretransplant psychiatric condition, age at transplant and sex) accounted for $61 \%$ of the variation of the dependent variable $(\mathrm{P}=0.033)$. Of the four predictor variables, this model identified two of the independent variables (abstinence for less than six months and female sex) as significant at the 0.05 probability level, while the other two were significant at the 0.1 probability level (Table 2 ).

The multivariate model predicted the outcome of $95 \%$ of the patients correctly. Five of the seven patients whom the model predicted to relapse to harmful drinking were indeed recidivists, yielding a positive predictive value of $71 \%$. One patient would have been incorrectly classified as recidivist by the model. Of the 56 cases in which the prediction was no relapse, two patients returned to harmful drinking yielding a negative predictive value of $96 \%$ according to this model. The sensitivity of the model was $71 \%$, with a specificity of $98 \%$.

Of the 80 patients, 28 were deceased at the time of study (Table 3). The most common causes of death included hepatitis C recurrence $(18 \%)$, sepsis post-transplant $(14 \%)$ and cancer $(11 \%)$, of which only one patient died from hepatocellular carcinoma. However, the cause of death in 11 patients was unknown or the records were unavailable. Of clinical
TABLE 1

Univariate analysis of potential risk factors for recidivism

\begin{tabular}{|c|c|c|c|}
\hline & $\begin{array}{l}\text { Nonrelapse } \\
\quad(n=72)\end{array}$ & $\begin{array}{l}\text { Relapse } \\
(n=8)\end{array}$ & $P^{*}$ \\
\hline Male:female & $57: 15 / 72(79: 21)$ & $3: 5 / 8(38: 62)$ & 0.021 \\
\hline Caucasian & $50 / 56(89)$ & $7 / 8(88)$ & 1.000 \\
\hline Currently alive & $42 / 66(64)$ & 4/8 (50) & 0.467 \\
\hline $\begin{array}{l}\text { Age at transplant, years, } \\
\text { mean } \pm \text { SD (median) }\end{array}$ & $\begin{array}{l}51.2 \pm 6.8 \\
(51.0)\end{array}$ & $\begin{array}{c}43.9 \pm 4.9 \\
(44.5)\end{array}$ & 0.004 \\
\hline Age at transplant, $<50$ years & $33 / 72(46)$ & 7/8 (88) & 0.057 \\
\hline $\begin{array}{l}\text { Alcoholic cirrhosis as one } \\
\text { diagnosis }\end{array}$ & $35 / 72(49)$ & $6 / 8(75)$ & 0.265 \\
\hline Hepatitis C coinfection & $34 / 72(47)$ & 1/8 (13) & 0.073 \\
\hline Hepatocellular carcinoma & $3 / 72(4)$ & $0 / 8(0)$ & 1.000 \\
\hline OLT performed before 1995 & 8/72 (11) & $2 / 8(25)$ & 0.261 \\
\hline \multicolumn{4}{|l|}{ Addiction behaviours } \\
\hline $\begin{array}{l}\text { Alcohol per day, g, mean } \pm \text { SD; } \\
\text { median (range) }\end{array}$ & $\begin{array}{r}59,141 \pm 110.3 \\
112(8-492)\end{array}$ & $\begin{array}{l}7,74 \pm 44.1 \\
56(25-146)\end{array}$ & 0.119 \\
\hline Drank liquor & $35 / 58(60)$ & $4 / 8(50)$ & 0.707 \\
\hline Drank beer & $38 / 58(66)$ & $4 / 8(50)$ & 0.448 \\
\hline Drank wine & $3 / 58(5)$ & 2/8 (25) & 0.107 \\
\hline $\begin{array}{l}\text { Abstinence pretransplant, } \\
\text { months; mean } \pm \text { SD (median) }\end{array}$ & $\begin{array}{c}63,53.2 \pm 62.3 \\
(26.0)\end{array}$ & $\begin{array}{c}\text { 7, 9.3 } \pm 8.1 \\
(9.0)\end{array}$ & $<0.001$ \\
\hline $\begin{array}{l}\text { Abstinent }<1 \text { year } \\
\text { pretransplant }\end{array}$ & 9/63 (14) & 4/7 (57) & 0.019 \\
\hline $\begin{array}{l}\text { Abstinent }<6 \text { months } \\
\text { pretransplant }\end{array}$ & 2/63 (3) & $3 / 7(43)$ & 0.006 \\
\hline Illicit drug use, including IVDU & $29 / 58(50)$ & $3 / 8(38)$ & 0.710 \\
\hline Tobacco use & $17 / 55(31)$ & $3 / 8(38)$ & 0.701 \\
\hline $\begin{array}{l}\text { History of alcohol-related } \\
\text { infractions }\end{array}$ & $15 / 55(27)$ & $0 / 8(0)$ & 0.181 \\
\hline $\begin{array}{l}\text { No rehabilitation/counselling } \\
\text { completed }\end{array}$ & $25 / 56(45)$ & $4 / 8(50)$ & 1.000 \\
\hline \multicolumn{4}{|l|}{ Psychosocial factors } \\
\hline Unemployed & $26 / 61(43)$ & $6 / 8(75)$ & 0.132 \\
\hline No family/friend support(s) & $11 / 56(20)$ & $4 / 8(50)$ & 0.079 \\
\hline No partner & $20 / 55$ (36) & 4/8 (50) & 0.467 \\
\hline $\begin{array}{l}\text { Increased personal } \\
\text { stressors }\end{array}$ & $19 / 55(35)$ & $6 / 8(75)$ & 0.050 \\
\hline Poor socioeconomic status & $22 / 55(40)$ & $6 / 8(75)$ & 0.124 \\
\hline $\begin{array}{l}\text { Psychiatric conditions } \\
\text { pretransplant }\end{array}$ & $11 / 57(19)$ & $5 / 8(63)$ & 0.018 \\
\hline $\begin{array}{l}\text { Psychiatric conditions } \\
\text { post-transplant }\end{array}$ & $17 / 57(30)$ & $5 / 8(63)$ & 0.108 \\
\hline
\end{tabular}

Data presented as $n / n$ (\%) unless indicated otherwise. *Fisher's exact probabilities for $2 \times 2$ tables, independent samples $t$ tests for continuous variables. IVDU Intravenous drug users; OLT Orthotopic liver transplant

interest, two of the patient deaths were directly attributable to recidivism, although alcohol was suspected to have been a factor in the third death.

Among the eight recidivists, pretransplant psychiatric illness was found in five - four of whom had a diagnosis of major depressive disorder and one with anxiety disorder (Table 4). In most cases, relapse was discovered on routine follow-up blood work, revealing rising liver enzyme levels with a subsequent admission of alcohol consumption. Two patients either selfreported or were reported by a family member. One was discovered to have relapsed after being found intoxicated by an emergency physician following a motor vehicle accident 
TABLE 2

Summary of risk factors by multivariate logistic regression analysis for recidivism

\begin{tabular}{lccc}
\hline & OR & SE & P \\
\hline Abstinent $<6$ months pretransplant & 77.07 & 1.743 & 0.013 \\
Female sex & 18.80 & 1.451 & 0.043 \\
Psychiatric condition pretransplant & 12.35 & 1.312 & 0.056 \\
Age $<50$ years & 101.13 & 2.428 & 0.057 \\
\hline
\end{tabular}

Note: The continuous variables, months of abstinence and age, were dichotomized as per clinical definition. OR (exponent of the beta coefficient) in the multivariate regression equation; SE Standard error; $P$ Statistical significance of the independent variable for recidivism ( $n=62$ patients [with $n=7$ recidivists] had nonmissing values for all the independent predictors). The $R^{2}$ of the model $=0.612$

\section{TABLE 3}

\section{Causes of death}

\begin{tabular}{lc}
\hline Total deaths, $\mathrm{n}$ & 28 \\
Hepatitis C recurrence & $5(17.9)$ \\
Sepsis & $4(14.3)$ \\
Cancer, total & $3(10.7)$ \\
$\quad$ Lung cancer & $1(3.3)$ \\
Gastric cancer & $1(3.3)$ \\
$\quad$ Hepatocellular carcinoma & $1(3.3)$ \\
Pneumonia & $2(7.1)$ \\
Recidivism & $2(7.1)$ \\
Rejection & $1(3.6)$ \\
Unknown & $11(39.3)$ \\
\hline
\end{tabular}

Data presented as $n$ (\%) unless indicated otherwise

(Table 5). The average time to restart alcohol consumption was 23.2 months post-transplant, with an average of $44.9 \mathrm{~g}$ of alcohol consumed per day after transplant.

\section{DISCUSSION}

ALD is among the most common indications for orthotopic LT. Several studies $(6,8,9,18)$ have documented the detrimental effects of post-transplant recidivism. In an era of organ donation shortages, it is increasingly important to identify risk factors that reliably predict a relapse to alcohol to select individuals who will derive the most benefit from their transplant, and to enable targeted counselling and intervention to prevent a return to harmful alcohol consumption. From a societal perspective, this becomes increasingly important because public perception of organ allografts 'going to alcoholics so they can drink again' will be detrimental to any efforts to enhance organ donation rates in Canada. Already, the BC Transplant Society has encountered one recent organ donor family who consented to donation only on the condition that the liver allograft not go to an alcoholic recipient (ie, directed donation).

\section{Strengths and limitations}

In the present study, the return to harmful drinking - not 'any drinking' - was chosen as the outcome of interest because it is a more clinically relevant outcome measure. All relapses were discovered either by post-transplant screening, admission by the patient or disclosure from a family member, or documentation of intoxication by community physicians. It is very possible that episodes of post-transplant relapse were not reported
TABLE 4

Psychiatric conditions in those who relapsed to alcohol use post-transplant

\begin{tabular}{ll}
\hline Depression & 4 \\
Anxiety disorder & 1 \\
No psychiatric conditions & 2 \\
Unknown & 1 \\
Total & 8 \\
\hline
\end{tabular}

Data presented as $n$

\section{TABLE 5}

\section{Post-transplant characteristics of recidivists}

\begin{tabular}{ll}
\hline Mean time to restart alcohol post-transplant, months (range) & $23.2(0-56)$ \\
Amount of alcohol post-transplant, g (median) & 44.9 \\
How relapse discovered, n/n & \\
Abnormal liver enzyme tests on routine follow-up & $4 / 8$ \\
Patient/family reported & $2 / 8$ \\
Found intoxicated by an emergency room physician & $1 / 8$ \\
Unknown & $1 / 8$ \\
\hline
\end{tabular}

or documented and that our results are an underestimate. However, given that most of the patients underwent regular laboratory and clinical follow-up by experienced physicians and nurses, it is less likely that a case of harmful drinking resulting in allograft compromise was missed. Another limitation was the relatively small number of recidivists. Finally, the population investigated in the present study was comparable with cohorts considered in other similar studies. Therefore, the findings should be generalizable to other patients with ALD being evaluated for LT.

\section{Comments on individual predictors}

The duration of abstinence before placement on an LT list remains a controversial issue. While many studies have reported that abstinence duration is a strong predictor of recidivism (19-23), others have found no such correlation (24). Most transplant centres continue to require a minimum of six months abstinence (12). In the present study, the strongest predictor of alcohol relapse after orthotopic LT was pretransplant abstinence of less than six months (OR 77.07; standard error [SE] 1.743; $\mathrm{P}=0.013)$. The clinical significance of this finding is that it underscores the need for transplant centres to remain objective in their decisions when confronted with the emotionally charged situation of a decompensated patient who has not fulfilled the necessary six months of abstinence (or may not be able to). The median period of abstinence among those who did not relapse was 26 months compared with only nine months in those who relapsed $(\mathrm{P}<0.0001)$, supporting the concept that the longer the abstinence, the lower the risk of relapse, independent of the six-month rule. In fact, it was later revealed that two of the relapsed patients continued to drink weeks before their transplant, and another within four months of surgery, although all had cut down substantially. Two of these recidivists died several years after their transplant from redevelopment of alcoholic cirrhosis. The importance of disclosure by community health care professionals to the transplant centre is underscored by these events. A recent study by Vanlemmens et al (18) showed a survival benefit for standard care and waiting 
versus immediate listing for LT for Child-Pugh stage B alcoholic cirrhosis, due in large part to the reversibility of ALD in some cases. Our experience has also shown that some patients with decompensated ALD referred for LT may improve with prolonged abstinence such that they are no longer considered transplant candidates (25). Importantly, Vanlemmens et al (18) also showed that continued alcohol consumption at any level post-transplant was associated with poor outcomes. This further supports the importance of adhering to a minimum period of six months abstinence.

From our data, we found older age at transplant to be a possible protective factor against recidivism (OR 0.82; SE 0.076; $\mathrm{P}=0.010$ ) by univariate regression (Table 6). The recidivist group was found to be slightly younger in median age at the time of transplant -51.2 years compared with 43.9 years in the nonrelapse group $(\mathrm{P}=0.004)$. Given the small absolute difference of 7.3 years and the fact that other similar studies have found older age as a risk factor for relapse (23), we are unsure of the significance of this association and whether it would be a reliable predictive factor. In our study, we found that having a psychiatric condition pretransplant was a strong risk factor for recidivism by univariate regression (OR 6.97; SE 0.804; $\mathrm{P}=0.016$ ). The psychiatric conditions observed were mainly depression (four of the eight recidivists) and anxiety disorder (one of the eight recidivists) (Table 4). This is an important predictor because it could potentially be modified through optimizing medical treatment, targeted counselling and efforts to improve an individual's psychosocial supports. Thus, this finding does not suggest that a history of mental illness should be deemed an exclusion from transplant consideration, but an indication for specific assessment and closer follow-up. A number of other studies have also reported a strong correlation between a history of depressive disorder and a greater risk of alcohol abuse after LT $(19,23,24)$.

Interestingly, female sex was a predictor of relapse to alcohol by univariate analysis (OR 6.33; SE 0.786; $\mathrm{P}=0.019$ ) and remained significant on multivariate analysis (OR 18.80; SE 1.451; $\mathrm{P}=0.043)$, although we concede that the confidence interval was wide. The data also reveals that four of the five patients who relapsed and suffered from depression or anxiety disorder were women. It is well documented that women are twice as likely to suffer from depression or anxiety disorder than men (26). Thus, the finding of female sex as a risk factor may be confounded by the higher prevalence of depression and anxiety disorder among women in the population studied as well as in the general population (27).

In the present study, we defined increased personal stressors as a longstanding source of anxiety and psychological tension causing impairment to an individual's daily life. Examples included marital problems, death of a partner or child, personal bankruptcy and exceptional financial stressors, major criminal issues and significant family illness. Increased personal stressors were identified by univariate regression as predictors of recidivism (OR 5.68; SE 0.864; $\mathrm{P}=0.044$ ). This is not surprising given that many of these individuals likely abused alcohol as a coping mechanism to deal with the increased personal stressors in their lives and, in most cases, these personal stressors were still present after their LT surgery. Thus, it is not surprising that they would have a higher chance of returning to harmful drinking. This raises the importance of trying to identify the

\section{TABLE 6}

Summary of univariate logistic regression analysis for recidivism

\begin{tabular}{lccccc}
\hline & OR & SE & $\mathbf{P}$ & $\mathbf{r}^{\mathbf{2}}$ & $\mathbf{n}$ \\
\hline Female sex & 6.33 & 0.786 & 0.019 & 0.144 & 80 \\
Age at transplant, years & 0.82 & 0.076 & 0.010 & 0.227 & 80 \\
Age at transplant <50 years* & 8.27 & 1.095 & 0.054 & 0.141 & 80 \\
Abstinence pretransplant, months & 0.86 & 0.065 & 0.016 & 0.382 & 70 \\
Abstinent <1 year pretransplant* & 8.00 & 0.844 & 0.014 & 0.171 & 70 \\
Abstinent <6 months pretransplant* & 22.87 & 1.049 & 0.003 & 0.245 & 70 \\
Increased personal stressors & 5.68 & 0.864 & 0.044 & 0.136 & 63 \\
Psychiatric conditions pretransplant & 6.97 & 0.804 & 0.016 & 0.169 & 65 \\
\hline
\end{tabular}

$n$ Number of patients with nonmissing values; OR (exponent of the beta coefficient) in the univariate regression equations; $P$ Statistical significance of the independent variable for recidivism; SE Standard error of estimates; $r^{2}$ Coefficient of determination

motivation for alcohol abuse in each patient during the pretransplant assessment and helping to either resolve the identified stressor, or to help the patient develop improved coping mechanisms through avenues such as support groups and better social integration.

\section{CONCLUSION}

While overall survival rates in patients with ALD undergoing LT are similar to patients with other causes of end-stage ALD, survival and overall outcomes have been shown to be compromised in patients who return to alcohol abuse $(6,7)$. Therefore, it is imperative to find reliable predictors of recidivism. In the present study, we found the duration of abstinence to be the strongest predictor of post-transplant recidivism, with pretransplant abstinence of less than six months strongly predictive of recidivism. Our findings strongly support the requirement of a minimum of six months of abstinence before orthotopic LT.

The main finding of our study is that abstinence from alcohol of less than six months, female sex, pretransplant psychiatric conditions, younger age at time of transplant and increased personal stressors are all associated with a return to harmful drinking after orthotopic LT.

DISCLOSURE: Statistical analysis was performed by Dr Eva Germann of the Department of Surgery, University of British Columbia, who was a paid statistical consultant for this study.

ACKNOWLEDGEMENTS: The authors sincerely thank Ms Clare Bannon and Ms Eileen Brooks of the BC Transplant Society, Ms Irene Tse and Ms Joann Harrigan of the Solid Organ Transplant Clinic of the Vancouver General Hospital for their dedicated clinical care of these patients.

\section{REFERENCES}

1. The Organ Procurement and Transplantation Network. Transplant year by diagnosis through March 28, 2008. < http://optn.org/ latestData/rptData.asp> (Accessed on January 4, 2009).

2. Martens W. Do alcoholic liver transplant candidates merit lower medical priority than non-alcoholic candidates? Transpl Int 2001;14:170-5.

3. Neuberger J, Adams D, MacMaster P, et al. Assessing priorities for allocation of donor liver grafts: Survey of public and clinicians. BMJ 1998;317:172-5. 
4. Nathan PE. Substance use disorders in the DSM-IV. J Abnorm Psychol 1991;100:356-61.

5. Gedaly R, McHugh PP, Johnston TD, et al. Predictors of relapse to alcohol and illicit drugs after liver transplantation for alcoholic liver disease. Transplantation 2008;86:1090-5.

6. Cuadrado A, Fábrega E, Casafont F, et al. Alcoholic recidivism impairs long term patient survival after orthotopic liver transplantation for alcoholic liver disease. Liver Transpl 2005;11:420-6.

7. Lucey MR, Carr K, Beresford TP, et al. Alcohol use after liver transplantation in alcoholics. Hepatology 1997;25:1223-7.

8. Pfitzmann R, Schwenzer J, Rayes N, et al. Long-term survival and predictors of relapse after orthotropic liver transplantation for alcoholic liver disease. Liver Transpl 2007;13:197-205.

9. Pageaux GP, Bismuth M, Perney P, et al. Alcohol relapse after liver transplantation for alcoholic liver disease: Does it matter? J Hepatol 2003;38:629.

10. Anand AC, Ferraz-Neto BH, Nightingale P, et al. Liver transplantation for alcoholic liver disease: Evaluation of a selection protocol. Hepatology 1997;25:1478-84.

11. Cacciarelli TV. Access to liver transplantation: Can we do a better job? Liver Transpl 2005;11:1318-9.

12. Kotlyar DS, Burke A, Campbell MS, et al. A critical review of candidacy for orthotopic liver transplantation in alcoholic liver disease. Am J Gastroenterol 2008; 103:734-43.

13. Lim JK, Keeffe EB. Liver transplantation for alcoholic liver disease: Current concepts and length of sobriety. Liver Transpl 2004;10:S31-8.

14. Mackie J, Groves K, Hoyle A, et al. Orthotopic liver transplantation for alcoholic liver disease: A retrospective analysis of survival, recidivism, and risk factors predisposing to recidivism. Liver Transpl 2001;7:418-27.

15. Bjornsson E, Olsson J, Rydell A, et al. Long-term follow-up of patients with alcoholic liver disease after liver transplantation in Sweden: Impact of structured management on recidivism. Scand J Gastroenterology 2005;40:206-16.
16. Gish RG, Lee A, Brooks L, et al. Long-term follow-up of patients diagnosed with alcohol dependence or alcohol abuse who were evaluated for liver transplantation. Liver Transpl 2001;7:581-7.

17. National Institute of Alcohol Abuse and Alcoholism. 2004 definition of binge drinking. <www.niaaa.nih.gov> (Accessed on December 15, 2008).

18. Vanlemmens C, Di Martino V, Milan C, et al. Immediate listing for liver transplantation versus standard care for Child-Pugh B alcoholic cirrhosis. A randomized trial. Ann Intern Med 2009;150:153-61.

19. DiMartini A, Day N, Dew MA, et al. Alcohol consumption patterns and predictors of use following liver transplantation for alcoholic liver disease. Liver Transpl 2006;12:813.

20. Foster PF, Fabrega F, Karademir S, et al. Prediction of abstinence from ethanol in alcoholic recipients following liver transplantation. Hepatology 1997;25:1469.

21. Perney P, Bismuth M, Sigaud H, et al. Are preoperative patterns of alcohol consumption predictive of relapse after liver transplantation for alcoholic liver disease? Transpl Int 2005;18:1292.

22. Dew MA, DiMartini AF, Steel J, et al. Meta-analysis of risk for relapse to substance use after transplantation of the liver or other solid organs. Liver Transpl 2008;14:159.

23. DeGottardi A, Spahr L, Gelez P, et al. A simple score for predicting alcohol relapse after liver transplantation. Arch Intern Med 2007;167:1183-8.

24. Kelly M, Chick J, Gribble R, et al. Predictors of relapse to harmful alcohol after orthotopic liver transplantation. Alcohol Alcohol 2006;41:278-83.

25. Alali J, Ramji A, Ho JK, et al. Liver transplant candidacy unsuitability: A review of the British Columbia experience. Can J Gastroenterol 2006;20:85-99.

26. Weissman MM, Olfson M. Depression in women: Implications for health care research. Science 1995;269:799-801.

27. Kessler RC, Chiu WT, Demler O, et al. Prevalence, severity, and comorbidity of 12-month DSM-IV disorders in the National Comorbidity Survey Replication. Arch Gen Psychiatry 2005;62:617-27. 


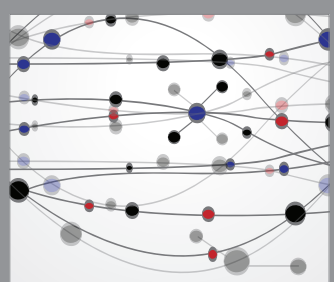

The Scientific World Journal
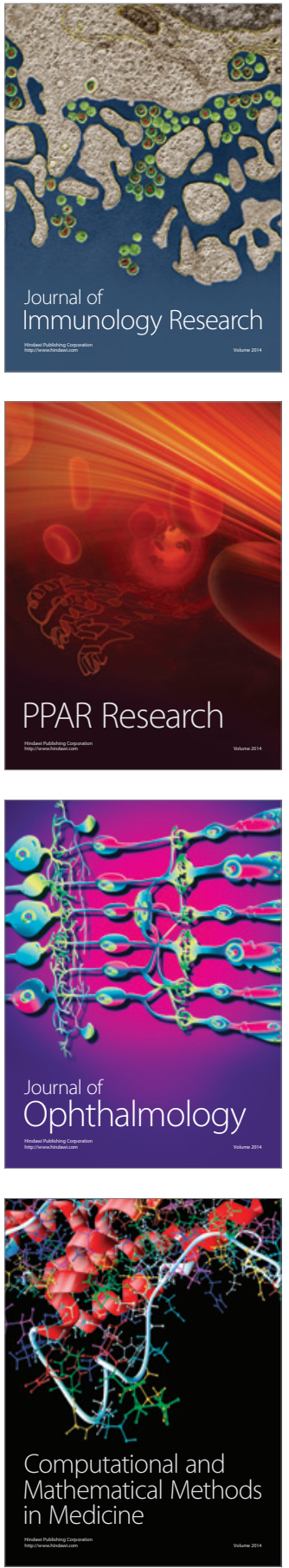

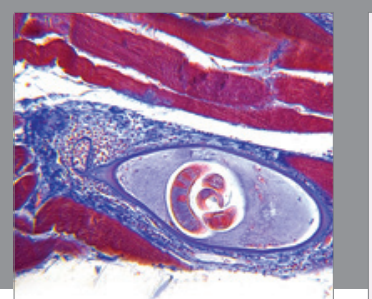

Gastroenterology Research and Practice

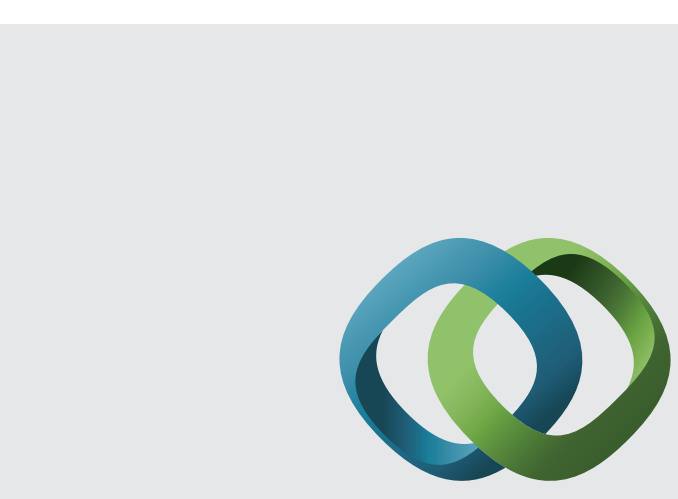

\section{Hindawi}

Submit your manuscripts at

http://www.hindawi.com
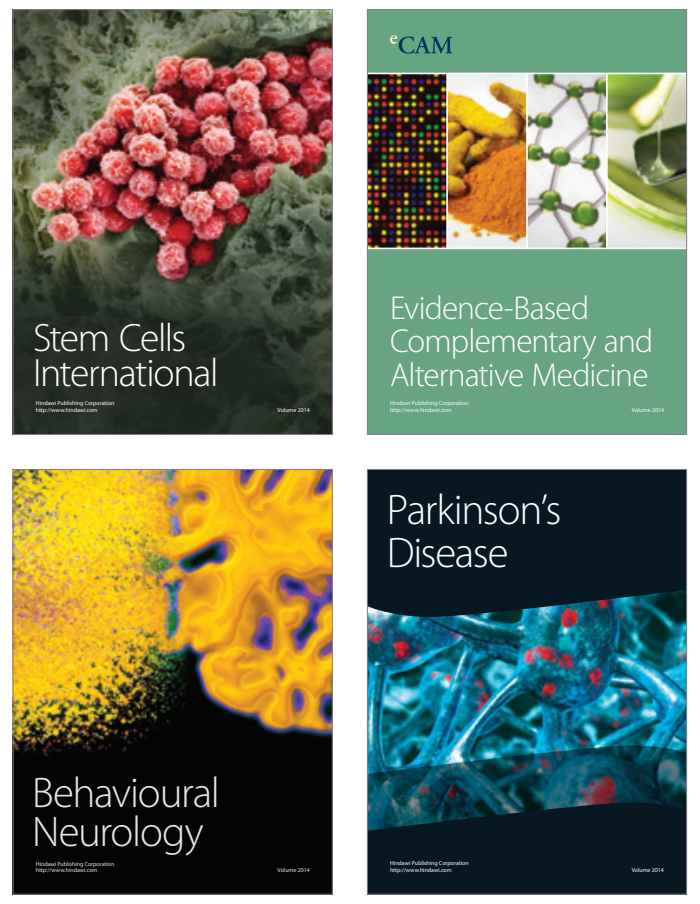
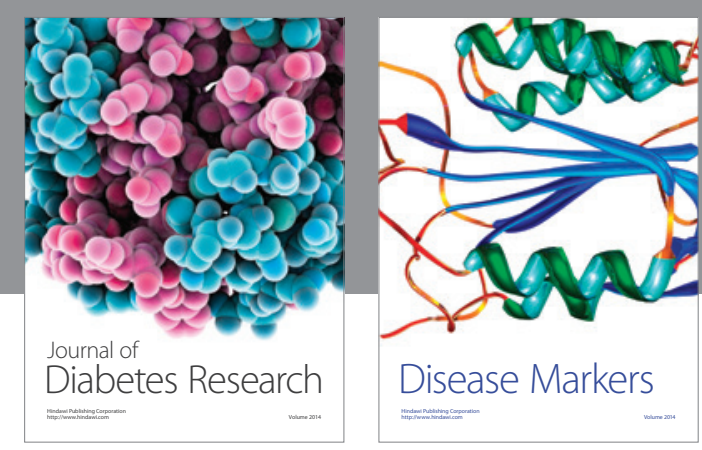

Disease Markers
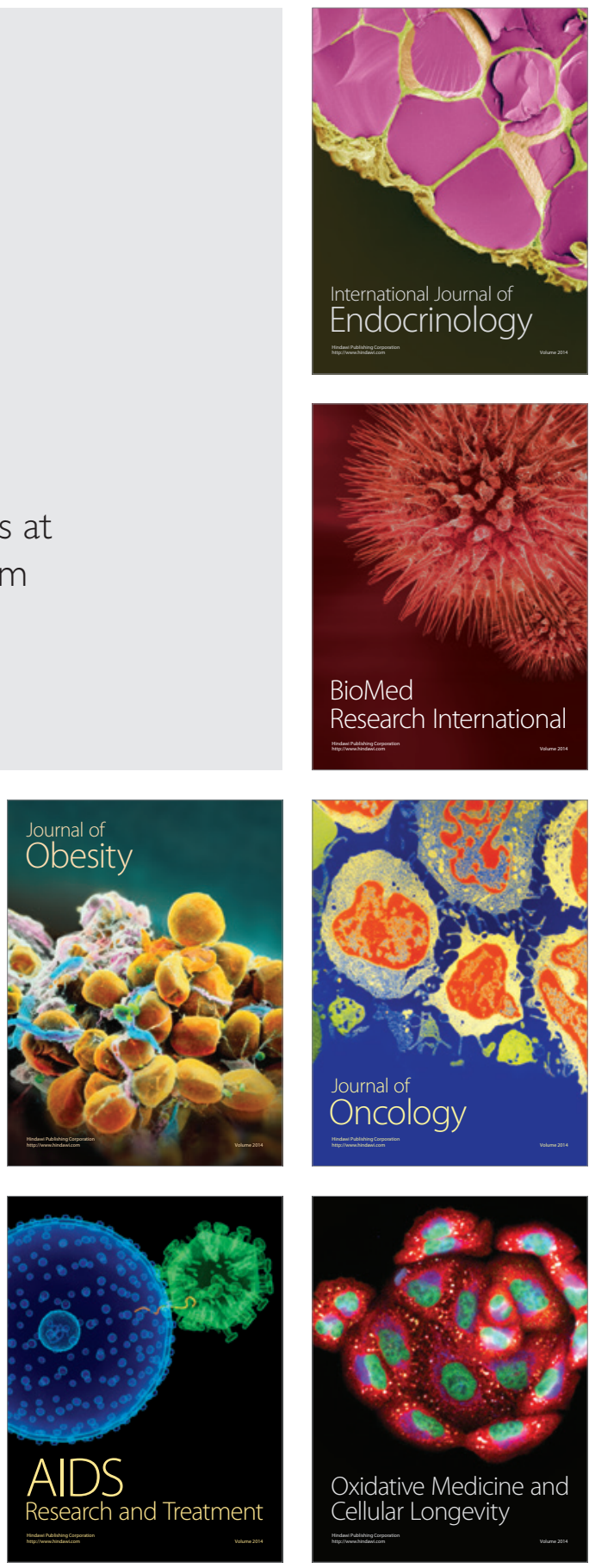